\title{
Candida Ciaccio
}

INSULARITÉ ET TOURISME; LES CAS DE LA SICILE ET DE LA SARDAIGNE

\section{CHARAKTER WYSPIARSKI TURYSTYKI PRZYKŁAD SYCYLII I SARDYNII}

\section{LA SPECIFICITE DU TOURISME DES REGIONS AUTONOMES INSULAIRES DANS LE CADRE ITALIEN}

La Sicile et la Sardaigne, à cause de leur position stratégique surla rcute du grand tourisme mediterranéen, auraient pu jouer un rôle important mais au contraire pour plusieurs raisons (accessiblité difficile, prix élevés, politiques de développement touristique en faveur du tourisme de luxie etc.) elles sont restées à l'écart des grands flux étrangers.

En effet, leur espace présénte aujourd'hui une dominante vacanciére et italienne.

Même si l'emprise spatiale du tourisme est de grande envergure (voir carte), les chiffres soulignent la pauvreté de cette activité dans le cadre italien.

On trouve en Sicile, $3,7 \%$ des lits hoteliers, $1,2 \%$ des lits extrahôteliers mais $11,3 \%$ des chambres en résidences secondaires; ainsi que $5,3 \%$ des arrivées totales hôteliéres et $5 \%$ des arrivées étrangéres hôteliéres et, respectivement, $4,4 \%$ et $5,2 \%$ des nuitées. Dans l'extrahôtellerie, on a $1,5 \%$ des arrivées totales, $1,9 \%$ des arrivées étrangéres, $0,9 \%$ des nuitées totales et $1,1 \%$ des nuitées étrangéres.

En Sardaigne, on a $2,4 \%$ des lits hôteliers, $1,3 \%$ des lits extrahôteliers, $3 \%$ des chambres en résidances secondaires, $2 \%$ des arrivées totales et $0,8 \%$ des arrivées étrangéres extrahôteliéres, $2 \%$ des nuitées totales et $1,3 \%$ des nuitées étrangéres hôteliéres, $1 \%$ des nuitées totales et $1 \%$ des nuitées étrangéres extrahôteliéres.

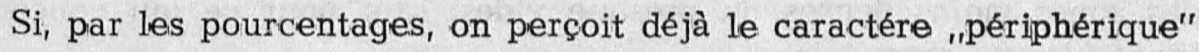
du tourisme des grandes îles italiennes en comparaison avec la pres- 
qu'île, les données chiffrées le soulignent encore plus (voir tableau I).

T ableau I

Dynamique du tourisme dans îles italiennes et dans-la presqu'île (1982) Dynamika turystyki na wielkich wyspach włoskich i na półwyspie (1982)

\begin{tabular}{|c|c|c|c|}
\hline Spécification & Italie & Sicile & Sardaigne \\
\hline Wyszczególnienie & Wlochy & Sycylia & Sardynia \\
\hline Lits hôteliers & 1585610 & 59183 & 38225 \\
\hline Extrahôteliers & 3098258 & 35712 & 40112 \\
\hline Chambres en résidence secondaire & 7185139 & 818161 & 211245 \\
\hline $\begin{array}{l}\text { Arrivées hôtelieres } \\
\text { Totales } \\
\text { Etrangéres }\end{array}$ & $\begin{array}{l}41602369 \\
14812017\end{array}$ & $\begin{array}{r}2189319 \\
751084\end{array}$ & $\begin{array}{l}817903 \\
125306\end{array}$ \\
\hline $\begin{array}{l}\text { Arrivées extrahôteliéres } \\
\text { Totales } \\
\text { Etrangéres }\end{array}$ & $\begin{array}{r}12470947 \\
3646550\end{array}$ & $\begin{array}{r}193066 \\
70911\end{array}$ & $\begin{array}{r}211919 \\
59181\end{array}$ \\
\hline $\begin{array}{l}\text { Nuitées hôteliéres } \\
\text { Totales } \\
\text { Etrangéres }\end{array}$ & $\begin{array}{r}170314229 \\
64605580\end{array}$ & $\begin{array}{l}7510757 \\
1598506\end{array}$ & $\begin{array}{l}3421352 \\
1719285\end{array}$ \\
\hline $\begin{array}{l}\text { Nuitées extrahôteliéres } \\
\text { Totales } \\
\text { Etrangéres }\end{array}$ & $\begin{array}{r}169485934 \\
36153533\end{array}$ & $\begin{array}{r}1598506 \\
403116\end{array}$ & $\begin{array}{r}1719285 \\
386450\end{array}$ \\
\hline
\end{tabular}

S o u c e: I dati del turismo in Italia, 1985, voll. 2, Milano, CESDIT.

En outre, il ne s'agit pas seulement d'un tourisme "péripherique" et, souvent, "aristocratique" mais aussi d'un tourisme trés concentré dans l'espace et dans le temps avec des pôles trés dévieloppés qui, il y a quelques années, ont été reliés par les résidences secondaires. C'est a dire qu'un espace de loisirs a crée les relais entre les espaces touristiques, graffés sur des installations ponctuelles. En effet, aujourd'hui surtout pour les littoraux de la Sicile, on peut parler d'urbanisation lineaire et de conurbations vacançiéres, qui se sont crées à partir de stations touristiques anciennes ou nouvelles.

Dans les deux îles, le découpage de l'espace touristique est assez nuancé: à côte de l'hypertourisme des stations, comme Taormina, Naxos, Cefalu en Sicile, la Costa Smeralda, la Gallura en Sardaigne, on trouve des zones moins denses ou presque vides, sauf pour ce qui concerne les résidences secondaires.

Les statistiques par departement (voir tableau II) soulignent bien le phénoméne, car les provinces intérieures ou les provinces dépour- 
Dynamique du tourisme en Sicile et en Sardaigne par département (1982)

Dynamika turystyki na Sycylii i Sardynii wg departamentów (1982)

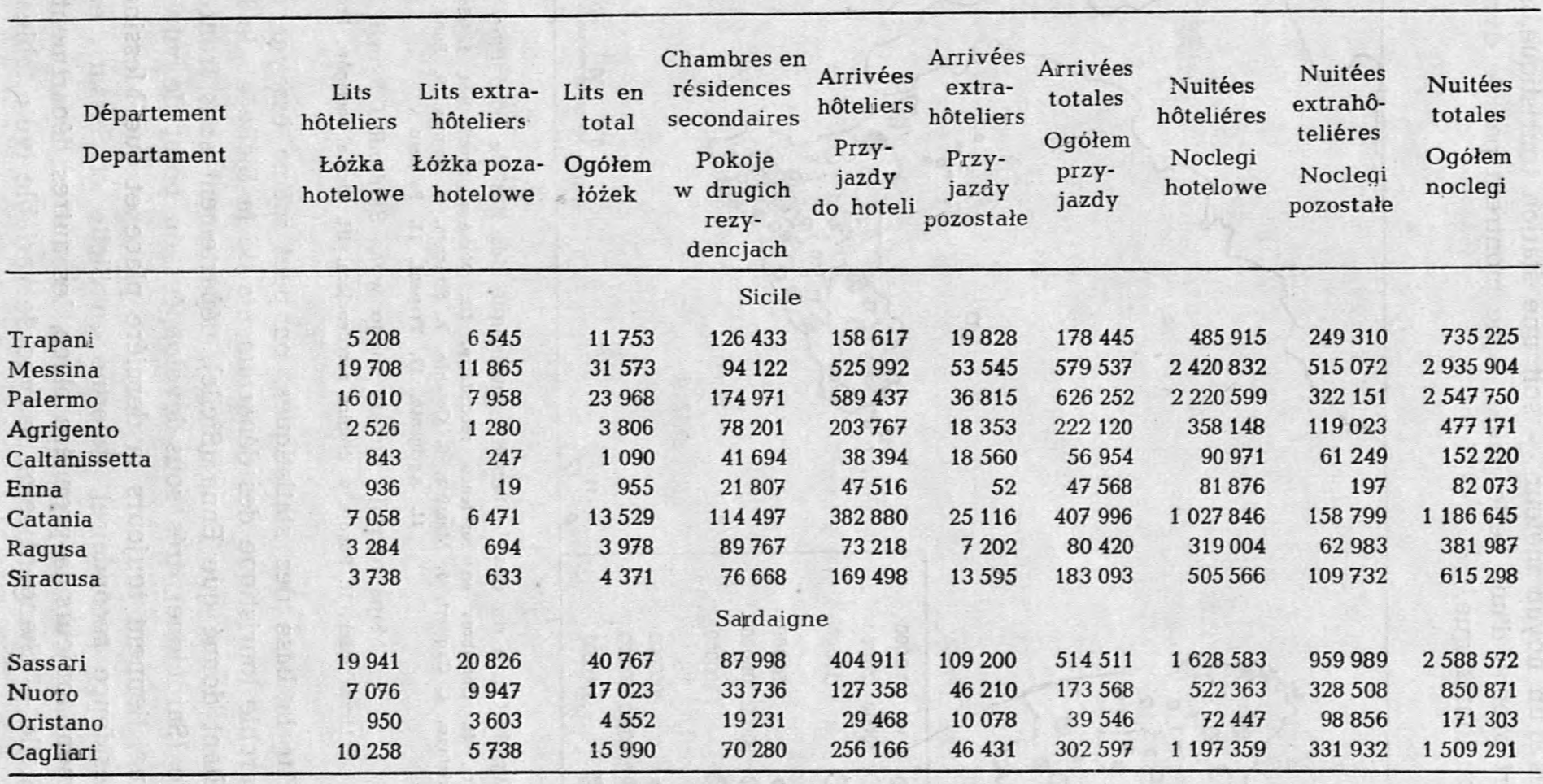


vues d'un noyau moteur - soit une station touristique, soit une ville d'art proche d'une belle plage - ne montrent pas de dynamisme à niveau touristique.

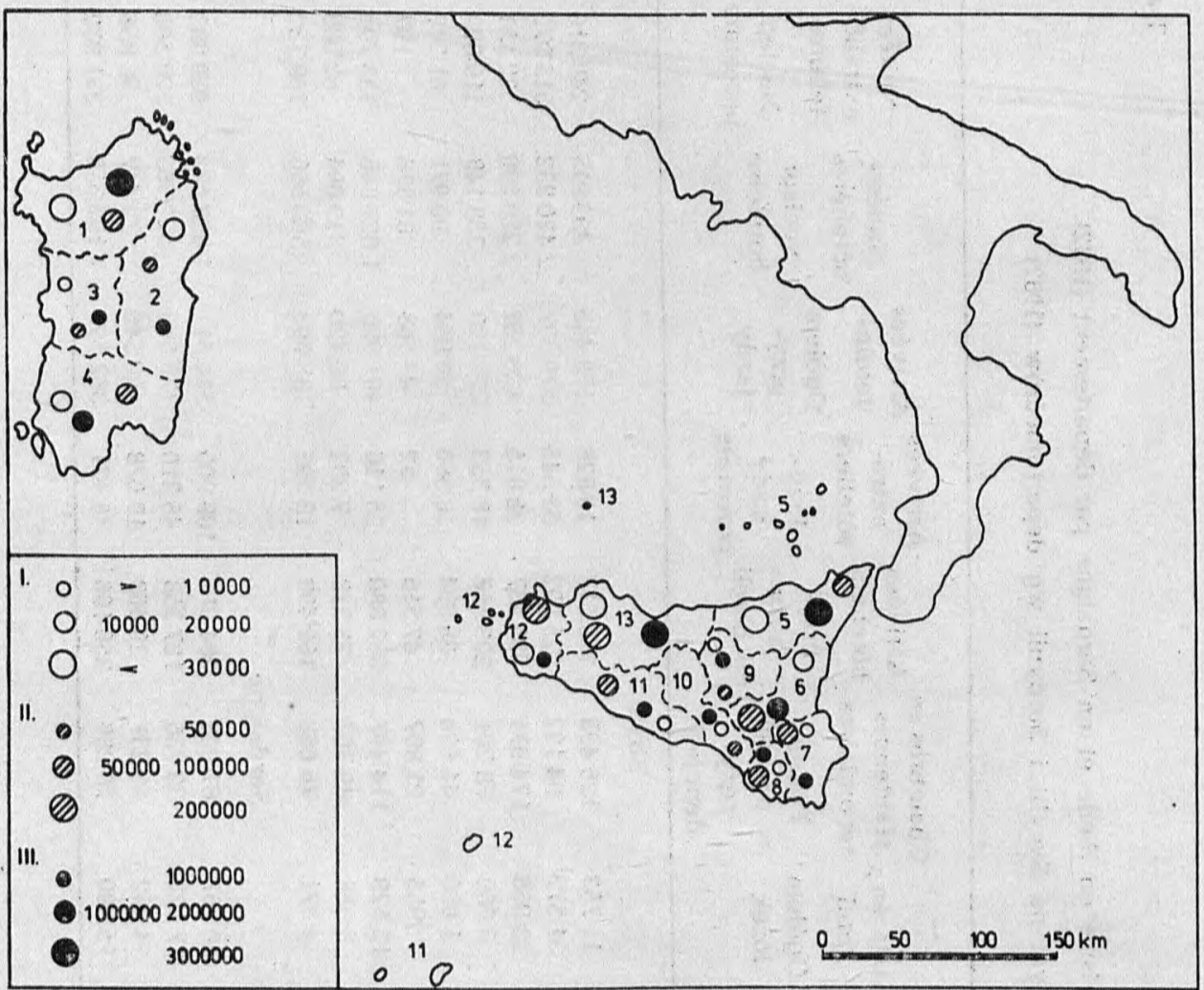

Fig. 1. Carte du developpement touristique des iles de Sardaigne et de Sicile

I. Lits, II. Chambres en residence secondaire, III. Nuitées, Provincies: 1. Sassari, 2. Nuoro, 3. Oristano, 4. Cagliari, 5. Messina, 6. Catania, 7. Siracusa, 8. Ragusa, 9. Enna, 10. Caltanissetta, 11. Agrigento, 12. Trapani, 13. Palermo

Mapa rozwoju turystycznego wysp Sardynii i Sycylii

I. Liczba 1óżek, II. Pokoje $w$ drugich rezydencjach, III. Liczba noclegów, Prowincje: ...

Sur la base des statistiques, on peut même essayer d'établir une hiérarchie touristique des départaments de la Sicile et de la Sardaignı.

Etant donné que Enna (Sicile), département sans front-mer, et Oristano (Sardaigne), trés sous-developpées du point de vue socio-économique, tiennent toujours la derniére place et que Messina (sauf pour la résidence secondaire), Palermo en Sicile et Sassari, en Sardaigne, tiennent toujcurs la premiére place, les autres départments - surtout en Sicile - changent selon le type de variable (voir tableau III). 
Hiérarchie des départements en Sicile et en Sardaigne

selon les facteurs choisis d'aménagement et de mouvement touristiques

Hierarchia departamentów na Sycylii i Sardynii

w świetle wybranych mierników zagospodarowania i ruchu turystycznego

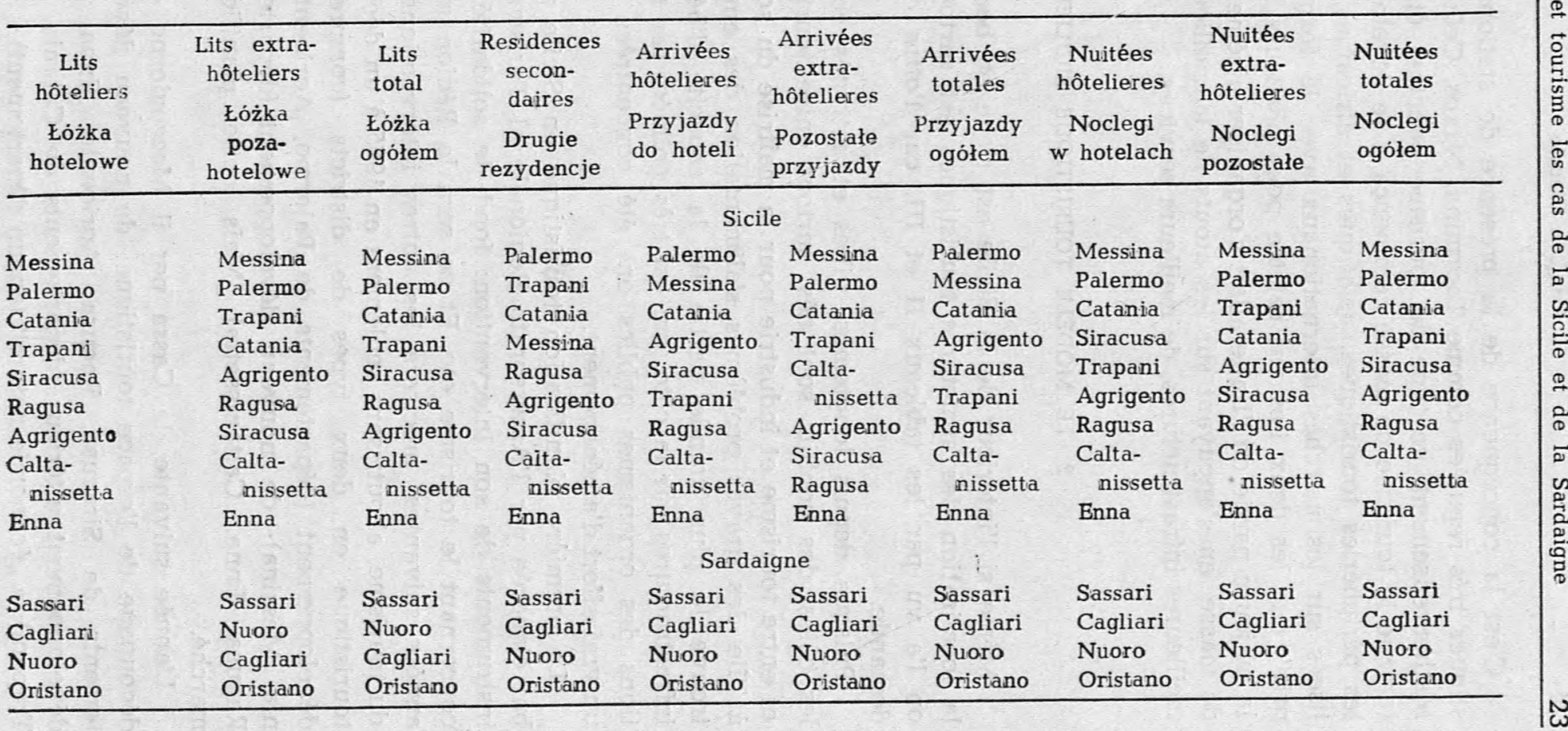


C'est la concéquence de la présence de stations ou régions touristiques trés reputées comme Taormina, Naxos, Cefialu, Costa Smeralda. Malheureusement, ce type de tourisme ponctuel était le seul existant lorsque le tourisme de masse commença a se développer et des nouvelles périphéries touristiques, asiatiques et africaines, furent commercialiseés sur les marchés internationaux avec la formule du "tout compris", que les deux îles ont rejetée pour plusieurs années. Entretemps, la majeure partie de l'Italie allait s'organiser aisément pour le tourisme de masse, en s'appuyant sur les atouts de la meilleure accessibilité, de meilleures infrastructures, de meilleurs services.

\section{LE MODELE TOURISTIQUE SICILIEN}

Même si l'intérieur de la Sicile est riche en beautés et artistiques, la localisation des structures touristiques est surtout littorale, comme on l'a vu par les tableaux II et III, car l'offre doit s'adapter à la demande.

Puisque depuis longtemps, villes et activités économiques lonqent les côtes, des conflits sont nés, surtout entre tourisme et agriculture et entre tourisme et industrie pour la maîtrise du sol, de l'eauqui pose à l'île des graves problèmes s'alimentation des emplois. En effet, on trouve la plus grande partie de la capacité d'hébergement et des infrastructures sur la côte, qui est très polluée, car toutes les interventions des organismes publics ont été concentrées les littoraux, sans un vrai effort d'aménagement.

La première planification touristique en Sicile remonte à 1951 et but élaborée par l'Assessorato Regionale al Turismo, qui organisa les instruments de son intervention: fond de solidarité hôteliere, travaux concernant le tourisme etc. Et ce sera la Région même qui, dans les années suivantes, précisera les autres interventions dans le tomaine du tourisme, aboutissant seulement en 1965 à un découpaqe de l'espace touristique en deux types de districts (comprensori): d'ultérieur développement (départements de Palermo, Aqrig̣ento, Siracusa, Càtənia, Messina); de nouveau développement (départements de Trapani, Ragusa, Enna, Caltanissetta). Mais cette planification n'a jamais marché.

L'année suivante, la Cassa per il Mezzoqiorno envisaqe un autre découpage de l'espace touristique: de nouveau dévelopipement (iépartements de Siracusa, Raqusa, Agrigento, Enna, Caltanissetta), de développement ultérieur (départements de Catania, Palermo, Messina, Trapani); a "économie nature" (aucun département). 
Ce découpagre, en 1977, sera accepté par le "Comitato Regionalie per la Programmazione turistica" avec des petites modifications car, entretemps, l'industrie, surtout l'industrie lourde et polluante, s'est développée sur la côte orientale (près de Siracusa), sur la côte occidentale (Gela) et sur la côte septentrionale (Termini, Milazzo).

Ce dernier aménagement, greffé sur des "progetti obiettivo", devait être rappele dans les Plans Directeurs et d'Urbanisation communaux.

La planification de la Région et de la Cassa del Mezzogiorno, naturellement, était indicative, non imperative et pourtant, les promoteurs privés, particuliers ou sociétés tels que Valtur, Club Méditerranée etc., ont bâti les structures avec des subventions publiques tandis que les pouvoirs publics, généralement, ont mis en place les infrastructures.

C'est en effet avec la contribution de la Cassa del Mezzogiorno, véritable organisme suprarégional, que les efforts les plus concrets ont été faits et que la course aux investissement a été amorcée même si la spatialisation du tourisme qui voulait entrainer un processus de développement touristique de l'intérieur de l'île a fait faillite; presque $90 \%$ des structures et, partant des flux se concientrent sur les littoraux.

Ce modèle de développement pose deux problèmes: la surchar e des côtes pendant l'été et la réduction de l'aariculture, car l'urbanisation a aisément envahi les espaces agricoles, avec la collaboration des propriétaires fonciers grands et moyens, qui ont vu un déhouché trés rentable, pendant la période de crise de l'agriculture, dans la transformation du sol agricole en sol à batir.

Mais, malgré les aides des pouvoirs publics et les investissements privés, la Sicile, comme la Sardaigne, n'a pas su s'emparer d'une partie interessante des flux touristiques à la recherche des îles.

Aıprès la deuxiéme auerre mondiale, le tourisme commence à décoller en 1954 et il progresse sans arrêt jusqu'en 1961, même sî n'est jamais supérieur à $6,3 \%$ du mouvement touristique en Italie (1956). Des années, 60 jusqu'à nos jours, l'allure est toujours discontinue. En effet, à partir de 1961, les arrivées et les nuitées s'accroissent de façon évidente jusqu'en 1983, meme evec dès phases de recul entre 1962 et 1966, en 1968, en 1981, en 1983 (voir tableaux IV); toutefois, on ne peut pas parler de "boom touristique".

On peut expliquer les phases de recul par le déplacement de la "nouvelle frontière" du tourisme méditerranéen, qui etait ren-esentée par la Sicile jusqu'à la moitié des années '60 vers sud ou vers les pays asiatiques, tandis que le recul d'une seule année est lịe à des 
Mouvement touristique en Sicile (en miliers)

Ruch turystyczny na Sycylii (w tysiącach)

\begin{tabular}{|c|c|c|c|c|c|c|}
\hline \multirow{4}{*}{$\begin{array}{c}\text { Années } \\
\text { Rok }\end{array}$} & \multicolumn{3}{|c|}{ Arrivées } & \multicolumn{3}{|c|}{ Nuitées } \\
\hline & & Przyjazdy & & & Noclegi & \\
\hline & Italiennes & etrangères & totales & Italiennes & etrangères & totales \\
\hline & Włosi & cudzoziemcy & ogółem & Włosi & cudzoziemcy & ogółem \\
\hline 1961 & 1131 & 217 & 1348 & 3606 & 928 & 4536 \\
\hline 1962 & 1125 & 238 & 1364 & 3484 & 997 & 4482 \\
\hline 1963 & 1111 & 224 & 1336 & 3404 & 942 & 4347 \\
\hline 1964 & 1109 & 231 & 1340 & 3206 & 910 & 4117 \\
\hline 1965 & 1072 & 247 & 1320 & 3150 & 934 & 4085 \\
\hline 1966 & 1094 & 279 & 1374 & 3093 & 1131 & 4224 \\
\hline 1967 & 1125 & 293 & 1419 & 3224 & 1188 & 4413 \\
\hline 1968 & 1062 & 186 & 1249 & 3073 & 811 & 3884 \\
\hline 1969 & 1156 & 293 & 1450 & 3181 & 1256 & 4437 \\
\hline 1970 & 1192 & 356 & 1549 & 3365 & 1520 & 4886 \\
\hline 1971 & 1195 & 386 & 1582 & 3458 & 1695 & 5154 \\
\hline 1972 & 1258 & 434 & 1692 & 3808 & 1942 & 5750 \\
\hline 1973 & 1199 & 418 & 1617 & 3751 & 1841 & 5593 \\
\hline 1974 & 1210 & 405 & 1615 & 3995 & 1805 & 5801 \\
\hline 1975 & 1222 & 426 & 1648 & 4107 & 1948 & 6056 \\
\hline 1976 & 1262 & 526 & 1788 & 4049 & 2406 & 6455 \\
\hline 1977 & 1290 & 566 & 1856 & 4267 & 2492 & 6760 \\
\hline 1978 & 1363 & 652 & 2016 & 4657 & 2802 & 7460 \\
\hline 1979 & 1380 & 770 & 2150 & 4701 & 3342 & 8044 \\
\hline 1980 & 1459 & 767 & 2226 & 4890 & 3536 & 8427 \\
\hline 1981 & 1518 & . 643 & 2161 & 5185 & 3040 & 8225 \\
\hline 1982 & 1560 & 821 & 2382 & 5365 & 3743 & 9109 \\
\hline 1983 & 1494 & 733 & 2227 & 5031 & 3251 & 8283 \\
\hline
\end{tabular}

S o u r c e: I dati del turismo...

raisons locales (le tremblement de terre de la Vallée du Belice en 1968, le choléra à Naples en 1973).

Naturellement, l'éloignement des pays émetteurs, qui empruntent die plus en plus l'avion, les structures discutables des aéroports siciliens et la politique de l'Alitalia ont joué un rôle important sur cette allure discontinue du mouvent touristique; mais, à la base, réellement, on trouve le manque d'un aménagiement organique et la politique gouvernementale toujours menée en faveur de l'industrie lourde.

C'est toujours la composante étrangère qui baisse, tandis que les Ittaliens augrementent quelque peu mệme si, souvent, au réseau hô- 
telier, ils préférent les campings-caravaning, les villagres-vacance, la résidence secondaire en propriéte ou en location.

On ne doit pas oublier que la Sicile est un pays de forte émigration et que pourtant beaucoup d'Italiens et d'étrangers, qui vienanent passer leurs vacances ici, sont des locaux.

La clientèle étrangère a un petit peu changé car, dans lès années '60 et '70, la dominante était allemande tandis que dans les années

Tableau V

Structure de la capacité d'hébergement en Sicile

Struktura bazy noclegowej na Sycylii

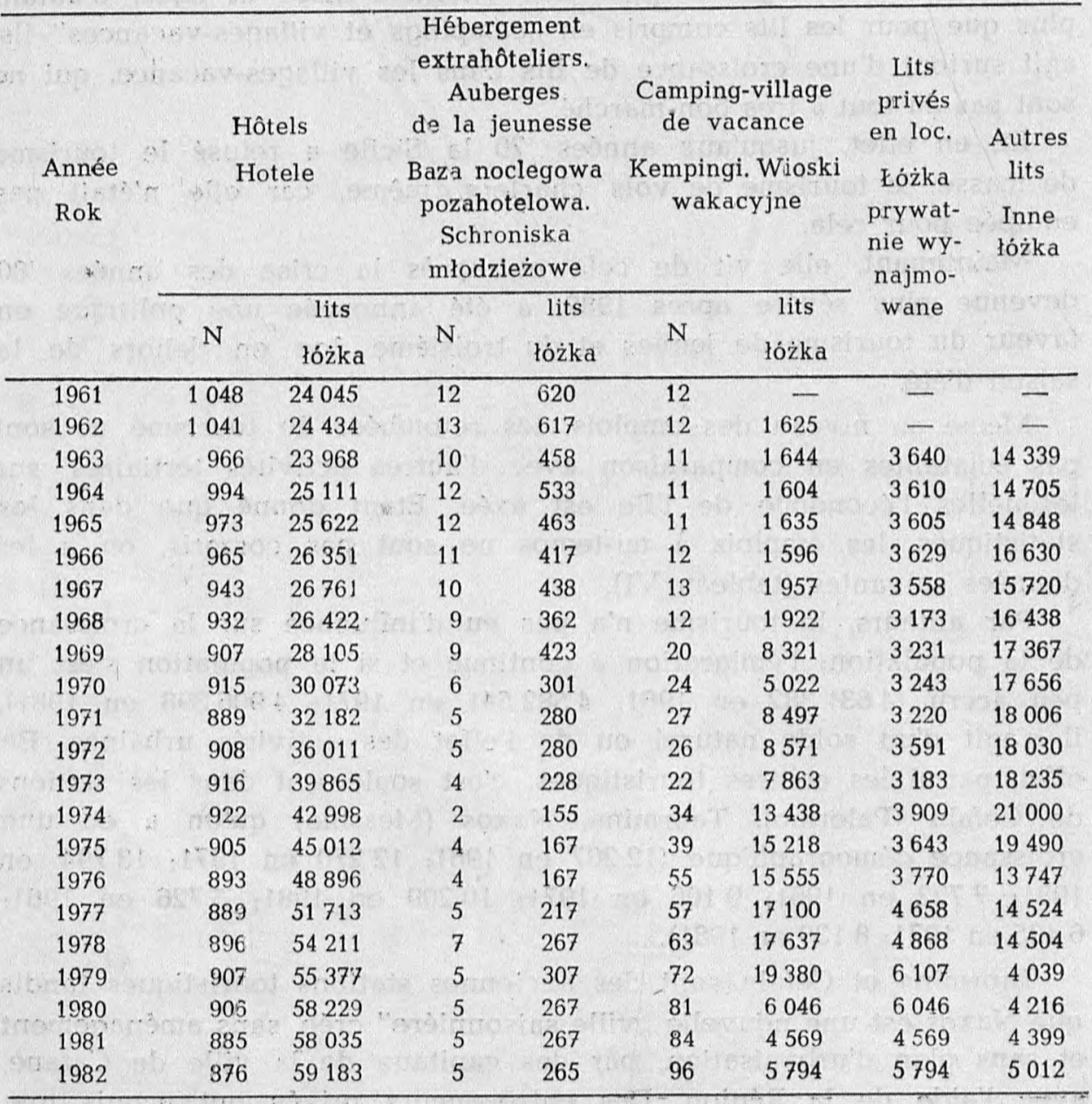

So u r c e: : dat del turismo... 
'80, elle est française, toujours suivie par les Americains, les Anglais, les Belges, les Autrichiens, les Suisses, les Scandinaves.

$\mathrm{La}$ capacité d'hébergement a beaucop augmenté (voir tableau V) depuis les années '60, mais surtout elle à changé de typologie: avant, on avait soit les hôtels à quatre étoiles, soit a une ou deux étoiles, tandis que maintenant on trouve un bon réseau d'hôtels à trois étoiles. Cette transformation est liée au fait que les hôtels construits avec l'aide de la Région ou de la Cassa del Mezzogiorno devaient obligatoirement appartenir à celte categorie même si leur standing était plus éleve. En générall, le nombre des hôtels a diminué car plusieurs instalations à une étoile ont été fermées.

Comme on le voit par les données chiffrées, l'espace touristique de la Sicile est organisé pour une clientéle aisée et agée, d'autant plus que pour les lits compris en "campings et villages-vacances" ils' agit surtout d'une croissance de lits dans les villages-vacance, qui ne sont pas du tout à tres bon marché.

Et, en effet, jusqu'aux années '70 la Sicile a refusé le tourisme de masse, le tourisme de vols charters, même, car elle n'était pas equipée pour cela.

Maintenant, elle vit de cela et, après la crise des années ' 80 devenue plus sévére apres 1982, a été annoncée une politique en faveur du tourisme de jeunes et du troisiéme âge en dehors de la saison d'été.

Même au niveau des emplois, les retombées du tourisme ne sont pas éclatantes en comparaison avec d'autres activités tertiaires, sur lesquelles l'économie de l'île est axée. Etant donné que dans les statistiques, les emplois à mi-temps ne sont pas compris, on a les données suivantes (tableau VI).

Par ailleurs, le tourisme n'a pas eu d'influence sur la croissance de la population; l'émigration a continué et si la population s'est un peu accru (4631382 en 1961; 4582541 en 1971; 4906398 en 1981), il s'agit d'un soldie naturel ou de l'effiet des activités urbaines. En effet, parmi les centres touristiques, c'est seulement dans les stations de Cefalu (Palermo), Taormina, Naxos (Messina) qu'on a eu une croissance démoạraphique (12 207 en 1961; 12270 en 1971; 13794 en $1981 ; 7722$ en $1961 ; 9106$ en $1971 ; 10209$ en $1981 ; 5726$ en 1961; 6425 en 1971; 8130 en 1981).

Taormina et Cefalu sont des anciennes stations touristiques tandis que Naxos est une nouvelle "ville saisonniére" crée, sans aménagement et sans plan d'urbanisation, par des capitaux de la ville de Catane, avec l'aide de la Région. Des entrepeneurs privéș ont acquis une grande propertété fonciére et ont crée environ 5000 lits hôteliers 
Emplois dans le tourisme en Sicile

Zatrudnienie w turystyce na Sycylii

\begin{tabular}{ccc}
\hline $\begin{array}{c}\text { Année } \\
\text { Rok }\end{array}$ & $\begin{array}{c}\text { Personnes } \\
\text { Osoby }\end{array}$ & $\begin{array}{c}\text { Pourcentage sur la population } \\
\text { active }\end{array}$ \\
\hline 1961 & 21100 & $\begin{array}{c}\text { Odsetek ludności aktywnej } \\
\text { zawodowo }\end{array}$ \\
1962 & 21900 & 1,39 \\
1963 & 21100 & 1,52 \\
1964 & 22000 & 1,48 \\
1965 & 20100 & 1,59 \\
1966 & 20400 & 1,46 \\
1967 & 20700 & 1,50 \\
1968 & 21800 & 1,49 \\
1969 & 22100 & 1,57 \\
1970 & 27100 & 1,60 \\
1971 & 25900 & 1,98 \\
1972 & 26500 & 1,88 \\
1973 & 27000 & 1,92 \\
1974 & 27600 & 1,95 \\
1975 & 27600 & 2,00 \\
1976 & 27300 & 2,02 \\
1977 & 28000 & 1,97 \\
1978 & 28400 & 2,01 \\
1979 & 30400 & 2,01 \\
1980 & 31300 & 2,13 \\
1981 & 31800 & 2,18 \\
1982 & 32800 & 2,19 \\
1983 & 33600 & 2,28 \\
\hline & & 2,33 \\
\hline
\end{tabular}

s o u c e: I dati del turismo...

dans 18 hotels et 14 pensions et plus de 12000 chambres en résıdences secondaires. Maintenant, Naxos est la concurrente la plus dangereuse ide Taormina.

On ne peut pas essayer de dresser un modèle du tourisme sicilien sans dire quelque mot sur le tourisme des petites îles, qui remonte dux années '70. Quatorze petites îles environnent la Sicile et reçoivent des flux exigus: 5195 lits hôteliers, 2521 lits extrahôteliers, 45409 arrivées hôteliéres, 13129 arrivées extrahôteliéres, 278710 nuitées hôteliéres, 137568 nuitées extrahôtéliéres.

L'organisation de l'espace touristique est en grande partie greftée sur la résidence secondaire et la dominante dies flux est italienne, concentrée dans les mois de juillet et d'août. Ce type de tourisme 
n'est pas intégré à l'agriculture et au milieu: au contraire, il est entré en conflit avec eux et les conditions de vie déjà sevéres, surrtout pour ce qui concerne le revitaillement en eau et l'alimentation, le sont devenues encore plus, même s'il a eu sur les tres pauvres des retombées tres intéressantes du point de vue économique et crée des emplois, même saisonniers.

Toutefois, si on peut parler d'hypertourisme dans quelques stationa touristiques ou dans quelques secteurs de résidences secondaires, pendant l'été, en général le tourisme en Sicile marche très lentement et ne donne ni les revenus ni les retombées en emplois, qui seraient attendus, si l'espace însulaire avait été amenagé, convenablement.

Ceci donne lieu à des dominantes estivales, vacanciéres et italien- nels et à un tourisme moyen, qui n'est pas dans la tradition, car la Sicile était née comme une région de tourisme d'hiver, hôtelier, étranger et de luxe.

\section{LE MODELLE TOURISTIQUE SARDE}

Même en Sardaigne, les structures touristiques sont localisées sur les littoraux, particulièrement dans là section nord-est de l'île.

Dans les années '50, les conditions socio-économiques et, partant soit l'état de la capacité d'hébrergement, soit l'intensité des flux touristiques, sont tres faibles.

La région sarde decida alors de créer en 1950 l'ESIT (Ente Sardo Industrie Turistiche) pour faire demarner le tourisme, quand elle vit le raz-de-marée touristique qui commençait à toucher d'autres iles.

L'ESIT dressa un plan de construction d'un réseau hôtelier qui débuta en 1954, avec l'aide financiére de la Région et de la Cassa del Mezzogiorno. Dans les premiers temps, les installationa sont dispersées, mais presqu'immédiatement on envisage des districts privilégiés: le golfe de Cagliari au sud, la côte de la Gallura au nord-ouest et la côte d'Alghero à l'ouest.

Beaucoup d'hôtels à trois étoiles ont été bâtis en une dizaine d'années lorsque, en 1964, débuta le Plan de Renaissance, valable pour 5 ans, qui avec la création de presque 15000 lits a realisés son programme, ainsi que le développement et l'amélioration du réseau de transports, aériens et maritimes, avec le contient. Les incitations de la Région et de la Cassa del Mezzogiorno, comme en Sicile, entraînent beaucoup de capitaux privés, particuliers et sociétés, et déjà, en 1961, le prince Aga Khan avait commencé la valorisation de la côte de la Gallura et l'opération pilote "Costa Smeralda". 
Il crée le consortium financier de la "Costa Smeralda" avec le but d'aménager de façon globale pour le tourisme de luxe $55 \mathrm{~km}$ de côtes sauvages dans le nord-est de l'île, dans le département de Sassari et, exactement, dans la commune d'Arzachena.

$\mathrm{Au}$ début, étaient prévus pôles de développement localisés dans 4 baies: au Nord Baia Sardinia et la presqu'île du Cap Ferro, au centre Porto Cervo, avec un port touristique et une "marina", et Peveno, au sud Cala Volpe. On devait construire 400000 lits en hôtels et en villages touristiques et 30000 chambres en résidences secondaires.

Cette emprise spatiale de grande envergure allait s'installer dans des propriétés fonciéres, rachétées par le consortium. On prevoyait de dépenser 450 a 500 milliards de lires italiennes entre 1964 et 1971.

Pendant la construction des bâtiments, les pouvoirs publics allaient aménager les réseaux routiers et les infrastructures (adduction d'eau et d'électricité, egoûts, téléphone, etc.). Mais, caus la deuxième moitié des années '70, l'opération piétine, les investissements représentent entre 100 et 150 milliands de lires italiennes et on parle de bâtir 60000 lits. La "Marina" est construite rapidment, tandis que les lits sont bâtis en deux phases: dans les années '60 les lits hôteliers, dans les années '70 les lits en résidences secondaires.

Naturellement, le projet "Costa Smeralda" a amorcé un processus ide développement touristique, mais très localisé sans diffusion à l'intérieur et qui a accientué les déséquilibres déjà existants.

Toutefois, son modèle à influencé tous les nouveaux équipements touristiques, car beaucoup de sociétés ont été crées, qui, à échelle breaucoup plus réduite, se sont emparé tranches les plus belles des littoraux sardes. Cette évolution a poussé, en 1978, les pouvoirs publics a découper l'espace însulaire en 25 districts, pour essayer de répandre le tourisme aussi à l'intérieur: mais seulement l'un entre eux, doué d'un grande façade littorale, à bien demanné.

Cependant, la capacité d'hebergement, pendant presque 20 ans a augmenté, comme on peut le voir par le tableau VII.

Il s'agit, comme en Sicile, d'un équipement qui peut être utilisé par une clientéle aisée et âgée.

Naturellement, 1/10 de la capacité d'hébergement ainsi que breaucoup de flux touristiques étrangers sont localisés dans la commune d'Arzachena. En effet, la Sardaigne n'a pu jouir du tourisme lointain car, dans les années '70, elle n'était pas bien équipée pour accueillir les flux des charters, qui ont préféré alors l'Espagne ou l'Afrique septentrionale, $\mathrm{n}_{\mathrm{i}} \mathrm{du}$ tourisme motorisé, même italien, à cause de l'accessibilité difficile. 
Tableau VII

Structure de la' capacité d'hébergement en Sardaigne

Struktura bazy noclegowej na Sardynii

\begin{tabular}{|c|c|c|c|c|c|c|c|c|}
\hline \multirow[t]{2}{*}{$\begin{array}{c}\text { Année } \\
\text { Rok }\end{array}$} & & & $\begin{array}{r}\text { Hél } \\
\text { extr } \\
\text { A } \\
\text { de } 1 \\
\text { Baza } \\
\text { poz } \\
\text { Sc } \\
\text { młc }\end{array}$ & $\begin{array}{l}\text { ement } \\
\text { teliers. } \\
\text { rges } \\
\text { unesse } \\
\text { legowa } \\
\text { elowa. } \\
\text { aiska } \\
\text { żowe }\end{array}$ & $\begin{array}{r}\text { Camp } \\
\text { de } \\
\text { Kempi } \\
\text { wa }\end{array}$ & $\begin{array}{l}\text {-village } \\
\text { cance } \\
\text { Wioski } \\
\text { cyjne }\end{array}$ & \multirow[t]{2}{*}{$\begin{array}{l}\text { Lits } \\
\text { privés } \\
\text { en loc. } \\
\text { Łóżka } \\
\text { prywat- } \\
\text { nie wy- } \\
\text { najmo- } \\
\text { wane }\end{array}$} & \multirow[t]{2}{*}{$\begin{array}{l}\text { Autres } \\
\text { lits } \\
\text { Inne } \\
\text { łóżka }\end{array}$} \\
\hline & $\mathrm{N}$ & $\begin{array}{c}\text { lits } \\
\text { łóżka }\end{array}$ & $N$ & $\begin{array}{c}\text { lits } \\
\text { lóżka }\end{array}$ & $\mathrm{N}$ & $\begin{array}{c}\text { lits } \\
\text { lóżka }\end{array}$ & & \\
\hline 1961 & 270 & 6010 & 7 & 312 & 10 & - & - & - \\
\hline 1962 & 267 & 6525 & 7 & 312 & 10 & 500 & - & - \\
\hline 1963 & 286 & 8318 & 7 & 312 & 10 & 518 & - & 3759 \\
\hline 1964 & 309 & 9988 & 7 & 312 & 11 & 1418 & - & 3957 \\
\hline 1965 & 299 & 11520 & 7 & 312 & 15 & 1637 & - & 3957 \\
\hline 1966 & 311 & 12218 & 7 & 312 & 15 & 1628 & 168 & 3957 \\
\hline 1967 & 325 & 13735 & 6 & 234 & 15 & 2042 & - & 3875 \\
\hline 1968 & 333 & 14792 & 6 & 234 & 18 & 3503 & - & 3875 \\
\hline 1969 & 346 & 16313 & 7 & 278 & 16 & 10243 & - & 3875 \\
\hline 1970 & 362 & 19526 & 6 & 280 & 15 & 13721 & - & 3876 \\
\hline 1971 & 380 & 20985 & 6 & 250 & 14 & 4309 & - & 3909 \\
\hline 1972 & 405 & 22450 & 5 & 216 & 18 & 5204 & - & 3909 \\
\hline 1973 & 436 & 24356 & 6 & 210 & 20 & 8462 & - & 3909 \\
\hline 1974 & 453 & 25518 & 5 & 256 & 26 & 13504 & 2588 & 6967 \\
\hline 1975 & 472 & 28370 & 6 & 244 & 29 & 13055 & 2578 & 6898 \\
\hline 1976 & 486 & 29518 & 6 & 244 & 40 & 18608 & 2805 & 410 \\
\hline 1977 & 477 & 31430 & 7 & 276 & 44 & 26277 & 11096 & 536 \\
\hline 1978 & 483 & 34235 & 7 & 276 & 49 & 25698 & 11096 & 536 \\
\hline 1979 & 493 & 35133 & 6 & 294 & 53 & 29264 & 600 & 953 \\
\hline 1980 & 504 & 36230 & 7 & 326 & 56 & 30695 & 1100 & 405 \\
\hline 1981 & 500 & 36529 & 6 & 292 & 60 & 36088 & 6977 & 388 \\
\hline 1982 & 519 & 382.25 & 7 & 336 & 55 & 37861 & 7600 & 316 \\
\hline
\end{tabular}

S o u c e: I dati del turismo...

Toutefois, le croissance des flux au total est intéressante et, au contraire de la Sicile, réguliére (voir tableau VIII) à l'exception de quelques années de stagnation due à la conjoncture.

La dominante, en Sardaigne, est aussi italienne et vacanciére. Parmi les étrangiers, la hiérarchie est la suivante: Allemands, Français, Suisses, Anglais. 
Tableau VIII

Mouvement touristique en Sardaigne (en miliers)

Ruch turystyczny na Sardynii (w tysiącach)

\begin{tabular}{|c|c|c|c|c|c|c|}
\hline $\begin{array}{c}\text { Année } \\
\text { Rok }\end{array}$ & $\begin{array}{l}\text { Arrivées } \\
\text { (total) } \\
\text { Przyjazdy } \\
\text { ogółem }\end{array}$ & $\begin{array}{c}\text { Nuitées } \\
\text { (total) } \\
\text { Noclegi } \\
\text { ogółem }\end{array}$ & $\begin{array}{l}\text { Arrivées } \\
\text { italiennes } \\
\text { Przyjazdy } \\
\text { Włochów }\end{array}$ & $\begin{array}{l}\text { Nuitées } \\
\text { italiennes } \\
\text { Noclegi } \\
\text { turystów } \\
\text { włoskich }\end{array}$ & $\begin{array}{c}\text { Arrivées } \\
\text { etrangeres } \\
\text { Przyjazdy } \\
\text { cudzo- } \\
\text { ziemców }\end{array}$ & $\begin{array}{c}\text { Nuitées } \\
\text { etrangeres } \\
\text { Noclegi } \\
\text { cudzo- } \\
\text { ziemców }\end{array}$ \\
\hline 1961 & 258 & 1376 & 227 & 1189 & 31 & 187 \\
\hline 1962 & 285 & 1521 & 254 & 1322 & 31 & 199 \\
\hline 1.963 & 294 & 1590 & 255 & 1370 & 39 & 220 \\
\hline 1964 & 323 & 1745 & 277 & 1433 & 45 & 311 \\
\hline 1965 & 338 & 1629 & 293 & 1303 & 45 & 326 \\
\hline 1966 & 375 & 1761 & 316 & 1368 & 58 & 392 \\
\hline 1967. & 352 & 1654 & 292 & 1238 & 59 & 415 \\
\hline 1968 & 386 & 1903 & 319 & 1412 & 67 & 491 \\
\hline 1969 & 449 & 2121 & 368 & 1545 & 81 & 576 \\
\hline 1970 & 499 & 2433 & 403 & 1684 & 95 & 739 \\
\hline 1971 & 540 & 2772 & 428 & 1802 & 112 & 970 \\
\hline 1972 & 559 & 2768 & 446 & 1868 & 112 & 900 \\
\hline 1973 & 590 & 2903 & 479 & 2016 & 110 & 886 \\
\hline 1974 & 621 & 3291 & 509 & 2402 & 112 & 889 \\
\hline 1975 & 652 & 3390 & 538 & 2490 & 113 & 900 \\
\hline 1976 & 704 & 3411 & 574 & 2473 & 130 & 937 \\
\hline 1977 & 762 & 3780 & 625 & 2772 & 136 & 1007 \\
\hline 1978 & 767 & 3849 & 622 & 2799 & 145 & 1049 \\
\hline 1979 & 783 & 4004 & 613 & 2754 & 170 & 1250 \\
\hline 1980 & 856 & 4267 & 685 & 3014 & 171 & 1252 \\
\hline 1981 & 932 & 4773 & 771 & 3673 & 160 & 1100 \\
\hline 1982 & 1029 & 5140 & 845 & 3915 & 184 & 1224 \\
\hline 1983 & 988 & 4960 & 824 & 3886 & 164 & 1073 \\
\hline
\end{tabular}

S o u r c e: I dati del turismo...

En ce qui concerne les emplois, les effets du tourisme sont presque du même niveau qu'en Sicile (voir tableau IX).

Mais la Sardaigne est beaucoup moins peuplée que la Sicile: 1418968 ab. en 1961, 1473500 en 1971, 2302834 en 1981. Evidemment la croissance de la population est la conséquence de la politique globale d'aménagement menée par la Région surtout grâce au Plan de Renaissance.

Ce plan a fait baisser les couts de l'insulatire et, avec l'opération "Costa Smeralda", a fait demarrer le tourisme qui, encore très concentré, grâce à la politique nouvelle des districts, pourra se ré- 
Tableau IX

Emplois dans le tourisme en Sardaigne

Zatrudnienie w turystyce na Sardynii

\begin{tabular}{ccc}
\hline $\begin{array}{c}\text { Année } \\
\text { Rok }\end{array}$ & $\begin{array}{c}\text { Personnes } \\
\text { Osoby }\end{array}$ & $\begin{array}{c}\text { Pourcentage sur la population } \\
\text { active }\end{array}$ \\
\hline 1961 & 7900 & $\begin{array}{c}\text { Odsetek ludności aktywnej } \\
\text { zawodowo }\end{array}$ \\
1962 & 8700 & 1,74 \\
1963 & 8100 & 1,91 \\
1964 & 9100 & 1,91 \\
1965 & 8000 & 2,12 \\
1966 & 8400 & 1,88 \\
1967 & 8600 & 1,96 \\
1968 & 9200 & 1,99 \\
1969 & 9600 & 2,12 \\
1970 & 11000 & 2,20 \\
1971 & 10800 & 2,50 \\
1972 & 11100 & 2,48 \\
1973 & 11300 & 2,56 \\
1974 & 11600 & 2,56 \\
1975 & 11800 & 2,61 \\
1976 & 11800 & 2,68 \\
1977 & 12300 & 2,59 \\
1978 & 12600 & 2,66 \\
1979 & 13100 & 2,69 \\
1980 & 14100 & 2,77 \\
1981 & 14000 & 2,93 \\
1982 & 14800 & 2,85 \\
1983 & 15000 & 3,08 \\
& & 3,10 \\
\hline
\end{tabular}

Sour ce: I dati del turismo...

pandre au moins sur les côtes, régions aujourd'hui les plus recherchées par les touristes, surtout dans les îles.

\section{LFS EXPERIENCE DES REGIONS INSULAIRES DANS LE DOMAINE DU TOURISME}

Comme on l'a vui, si les modèles sicilien ret sarde semblent être identiques en realité ils ont à la basie des différences importantes.

Dans les deux régions, c'est toujours le pouvoir central, par la Cassa del Mezzogiorno, qui a controlé l'évolution de l'espace touristique, même si ce sont les entrepreneurs privés qui ont bénéficié des 
incitations. Toutefois, en Sardaigne, ils ont du opérer dans un cadre précis d'aménagement.

En outre, en Sicile, les équipements touristiques sont arrivés avant les infrastructures tandis que, en Sardaigne, plus logiquement ce fut l'inverse.

On peut distinguer une autre grande différence dans le fait que, en Sicile, les nouvelles structures se sont greffées sur les anciennes, qui avaient déjà été mises en place au siécle dernier, tandis que en Sardaigne, tout l'équipement a été crée "ex nihilo". Même l'esprit avec lequel les enclaves néo-aristocratiques ont été crées est différent: la Sicile souhaitait, par cet outil, recuperer la clientèle du nord-Europe toujours décroissante, tandis que la Sardaigne voulait, de cette façon, devenir la "nouvelle frontiére" du "smart-set" international, voire la nouvelle Montecarlo ou la nouvelle Côte d'Azur.

Mais, ressemblanices et différences mises à part, le tourisme, avec sa littoralisation poussée a figé le modèle périphérie (côtes) - centre (intérieur), classique des grandes îles italiennes.

\section{BIBLIOGRAPHIE}

Actes du Colloque de Geographie du tourisme "Tourisme vie régionale dans les Pays mediterranéeus", 1975 (édité L. Pedrini), Ghigi, Rimini.

B andinu B., 1980, Costa Smeralda. Come nasce una favola, Milano, Rizzoli.

Boggio F., Pinna M., 1981, Il turismo in Sardegna, Atti del Convegno "La Sardegna nel mondo mediterraneo", Sassari, pp. 9-57.

Ciaccio C., 1975, Il recente svilluppo industriale e turistico della Sicilia, Ann. Fac. Economia e Commercio, Messina, 1, pp. 205-258.

Ciac cio C., 1979, Sviluppo turistico e agricoltura in Sicilia, Ann. Fac. Economia e Commercio, Messina, 1, pp. 151-176.

Ciaccio C., Turismo e microinsularita. Le isole minori della Sicilia, Bologna, Pataon.

Dragone M., 1979, La costa Smeralda e lo sviluppo turistico della Gallura, Riv. Geog. It., pp. $30-53$.

Loi Puddu G., 1968, Le développement touristique de l'ile de Sardaigne, "Cahiers du tourisme", CHET B4 Aix-en-Provence.

Pinna M., 1967, Il Piano di Rinascita della Sardegna nel quadro della pianificazione tegionale in Italia, Riv. Geog. It., pp. 121-149.

Rognant L., 1981, Types des régions touristiques en Italie, Fac. des Lettres et Sciences Humaines, Nice.

R ubino R., Orlandi. G., 1967, La pianificazione turistica in Sicilia, Palermo.

Candida Ciaccio

Institut di Geografia

Wplynęło:

dell Universita di Palermo

23 lipca 1987 r.

Italie 


\section{STRESZCZENIE}

Treść artykułu podzielona jest na 4 części. w których autorka omawia kolejno:

- specyfikę turyzmu w autonomicznym regionie wyspiarskich Włoch,

- sycylijski model turystyki,

- sardyński model turystyki,

- doświadczenia regionów wyspiarskich w turystyce.

Sycylia i Sardynia - mimo położenia na trasie wielkich, śródziemnomorskich potoków turystycznych - pozostają ciągle na uboczu. Głównymi powodami są: dość trudna dostępność, wygórowane ceny, polityka faworyzująca turystykę luksusową etc.

Autorka - zarówno w tekście, jak i w tab. I - przytacza liczby dotyczące wyposażenia $w$ miejsca noclegowe oraz wielkości ruchu turystycznego wskazujące na niezbyt dużą rolę wysp $\mathrm{w}$ porównaniu $\mathrm{z}$ całym Półwyspem Apenińskim. Specyfiką włoskiego turyzmu wyspiarskiego jest nie tylko jego „peryferyczność", lecz także "arystokratyzm" oraz jego koncentracja w czasie i przestrzeni. Centra turystyczne dobrze rozwinięte $w$ przeciągu kilku lat zostały połączone zabudową drugich rezydencji. Obecnie mamy do czynienia z urbanizacją linearną, którą tworzą stare i nowe stacje turystyczne.

Przytoczone $w$ tab. II liczby wskazują na zjawisko nierównomiernego rozwoju turystyki $w$ obrębie wysp. Prowincje wewnętrzne lub pozbawione siły motorycznej w postaci stacji turystycznej czy też miasta zábytkowego z plażą nie wykazują rozwoju turystycznego.

Mimo, iż wnętrze Sycylii posiada wyjątkowe walory naturalne i artystyczne, turystyka rozwija się glównie na wybrzeżach, bardzo zanieczyszczonych z racji koncentracji różnego rodzaju działalności gospodarczych.

Opracowany w $1951 \mathrm{r}$. plan zagospodarowania turystycznego nigdy nie był realizowany w praktyce. Podobnie, jak i plany zagospodarowania wykonane przez "Cassa per il Mezzogiorno" i zaakceptowane w 1977 r. przez "Comitato Regionale per la Programmazione Turistica". Plany te miały charakter tylko wskazujący a' nie nakazujący. Stąd też przedsiębiorcy prywatni, a szczególnie takie towarzystwa jak: "Valtur", "Club Méditerranée" etc., budowali na terenach już wyposażonych w infrastrukturę. W wyniku takiej działalności prawie $90 \%$ ruchu turystycznego koncentruje się na wybrzeżach.

W dalszej części artykułu autorka omawia rozwój ruchu turystycznego na Sycylii począwszy od 1961 do 1983 r. (tab. IV), wskazując na jego fazy oraz przyczyny słabego rozwoju. Do głównych zalicza brak odpowiedniego zagospodarowania turystycznego oraz politykę rządu faworyzującą rozwój przemysłu ciężkiego. Cechą charakterystyczną jest także zmniejszający się udział tuirystów zagranicznych. W latach sześćdziesiątych i siedemdziesiątych dominowali Niemcy, a w latach osiemdziesiątych obserwuje się znaczne rozszerzenie struktury narodowej (Francuzi, Amerykanie, Anglicy, Belgowie, Austriacy, Szwajcarzy, Skandynawowie). Część tej klienteli stanowią dawni emigranci włoscy lub ich rodziny.

Pojemność bazy noclegowej, począwszy od lat sześćdziesiątych znacznie się powiększyła. Zmieniła się także jej jakość (tab. V). Zmniejszyła się zwłaszcza liczba hoteli o niższym standardzie. Do lat siedemdziesiątych Sycylia była terenem głównie turystyki masowej, związanej z lotami charterowymi, mimo iż nie była do tego dobrze przygotowana. Obecnie, po kryzysie lat osiemdziesiątych faworyzowana jest - poza sezonem letnim - turystyka młodzieżowa oraz tzw. trzeciego wieku.

Turystyka na Sycylii odgrywa pewną rolę $w$ zatrudnieniu ludności (tab. VI). Nie ma natomiast wpływu na wzrost zaludnienia. Nadal obserwuje się emigrację 
ludności $\mathrm{z}$ wyspy. W niektórych tylko miejscowościach turystycznych odnotowano wzrost zaludnienia (Cefalu, Taormina, Naxos). Autorka wskazuje także na rolę turystyczną 14 małych wysp otaczających Sycylię.

Turystyczna baza noclegowa Sardynii zlokalizowana jest na wybrzeżach, głównie w północno-wschodniej części wyspy. Powstała ona po 1950 r., utworzono tu "Ente Sardo Industrie Turistiche". Opracowano wówczas plan budowy sieci hoteli, który był realizowany z pomccą finansową Regionu oraz "Cassa del Mezzogiorno". Przyciagnęło to kapitały prywatne, głównie różnych towarzystw. Powstało wówczas także konsorcjum finansowe "Costa Smerralda", którego celem było globalne zagospodarowanie dla turystyki luksusowej $55 \mathrm{~km}$ dzikích wybrzeży w północno-wschodniej części wyspy. Z przewidzianych zamierzeń zbudowano dość szybko dzielnicę "Marina". W latach sześćdziesiątych powstały hotele, zaś w siedemdziesiątych — drugie rezydencje. Projekt "Costa Smeralda" rozpoczął proces rozwoju turystycznego. Na przestrzeni 20 lat znacznie powiększyła się pojemność turystycznej bazy noclegowej (tab. VII). Baza ta wykorzystywana jest głównie przez klientelę starszą i raczej bogatą

Rozwój ruchu turystycznego na Sardynii $-\mathrm{z}$ wyjątkiem kilku lat stagnacji jest regularny (tab. VIII). Podobnie jak na Sycylii dominują Włosi. Odsetek ludności aktywnej zatrudnionej w turystyce jest także podobny (tab. IX).

Tirystyczny model sycylijski i sardyński wydaje się być podobny. W rzeczywistości jednak są one tworzone na różnych podstawach. Na Sycylii wyposażenie turystyczne było wcześniejsze niż infrastruktura, na Sardynii - odwrotnie. Na Sycylii nowe struktury są tworzone na bazie starych, $\mathrm{z}$ ubiegłego wieku, podczas gdy na Sardynii całe wyposażenie turystyczne było tworzone od nowa. Sycylia chciałaby odyzskać klientelę północnoeuropejską, podczas gdy Sardynia chciałaby stać się nowym Monte Carlo czy też nowym Côte d'Azur.

Streszczenie opracowała Elżbieta Dziegieć 